\title{
慣性センサを使用したフライングディスクの運動力学推定 Estimation of the flying disc dynamics using the inertia sensor
}

\author{
O正 小柳 玲乃（慶應義塾大院） \\ Reno Koyanagi \\ 正仰木 裕嗣（慶應義塾大） \\ and Yuji Ohgi \\ ${ }^{*}$ Graduate School of Media and Governance, Keio Univ., Endo 5322, Fujisawa, Kanagawa, 252-8520, JAPAN
}

\begin{abstract}
The purpose of this research is to estimate the angular velocity and direction of the rotational axis of the flying disc by inertia sensors. A subject performed throwing by using the flying disc attached the accelerometer. The closed up release and catching point images were acquired using the high speed cameras. The angular velocity was estimated from the centrifugal and angular acceleration. And rotational axis was estimated using gyroscope and accelerometer Estimated angular velocity and rotational axis were compared to the calculated angular velocity by the cameras.
\end{abstract}

Key Words: Flying disc, Frisbee, Inertia sensor, Angular velocity, Rotational axis

1.はじめに

野球やサッカー，槍投げ，円盤投げなど物体が飛翔運動を 行う競技において, 飛翔中の投射体の姿勢や速度などの変量 を計測することは流体力学的見地による現象の解明のみな らず, 競技者のスキルを計測するという点においても非常に 重要である. 現行では飛翔体の力学量を求める際主に映像解 析, 及び風洞実験装置を使用する計測手法が採用されている。 しかしこれらの計測手法は実投射された対象を連続して計 測するという点に関していくつかの問題が存在する.風洞害 験装置は実投射された飛翔体の計測は不可能であり，赛投射 された飛翔体の力学量を求めるには推定が必要となる.実投 射された飛翔体を計測する際に用いられる手法として映像 解析手法が挙げられるが, 広範囲を移動する対象や高速で移 動する対象の観察は位置情報を取得する機器の機構上この 計測法では非常に困難である. 対して本研究で提案する慣性 センサを飛翔体に装着及び内蔵させ, センサの值から物理量 を推定する手法は観察対象となる物体を計測時に実際に飛 翔させることが可能である.また映像解析手法を使用した際 の計測範囲が制限される問題を考慮せずに飛翔体を観察す ることが可能である.

フライングディスクもまたスポーツにおける飛翔体の一 つであり, ディスクの角速度, 回転軸や空気力がディスクの 飛翔という物理現象を捉える際に非常に重要なパラメータ である.

今までの研究では 3 軸加速度計を使用し, ディスクの裹に 固定することによって角速度や回転軸の方向を推定した. し かし, フライングディスクや円盤投げなどで観察される飛翔 中に回転軸が変化する現象は 3 軸加速度計では観察が不可 能であった. そこで 3 軸加速度計の他に 2 軸ジャイロスコー プを使用して角速度，回転軸の方向を推定した。

\section{2. 計測器具, 実験}

慣性センサをディスクの裏面に固定し，投射実験を行った， 3 軸加速度計の時間分解能は $1000 \mathrm{~Hz}$, 計測レンジは $12 \mathrm{G}$ で制作し， 2 軸ジャイロスコープの時間分解能は $1000 \mathrm{~Hz}$, 計測レンジは $200 \mathrm{deg} / \mathrm{s}$ に設定し，計測を行った。ジャイロ スコープの軸は加速度計の $\mathrm{x}$ 軸及び $\mathrm{y}$ 軸に平行となるように 設定した.

このようにして製作したフライングディスクを被験者に 投げてもらい,そのリリース付近及びディスクの飛翔期終端 部をそれぞれ高速度カメラ 2 台ずつ, 合計 4 台使用し飛翔期 のディスクを撮影した. 高速度カメラのサンプリングレート はそれぞれ $1000 \mathrm{~Hz}$ で撮影した。ささらに高速度力メラから角 速度及び回転軸の方向を計測するため絶対座標系を定義し た. 鉛直方向を Z 軸, ディスクの進行方向を $\mathrm{X}$ 軸, 右手座 標系に従い X，Z 軸双方に垂直な軸を $\mathrm{Y}$ 軸とした。
また加速度計の各 3 軸にそれぞれが平行であり, ディスク の中心を原点としたセンサ座標采を Fig. 1 のように設定し た. 加速度及びジャイロスコープから回転軸の方向を推定す る際, 計測值はセンサ座標系で出力される. そのため比較を 行う際にセンサ座標系を高速度カメラから取得したデータ を使用して絶対座標系に座標変換し各值を比較した. 実験の 概要は Fig. 2 のとおりである.

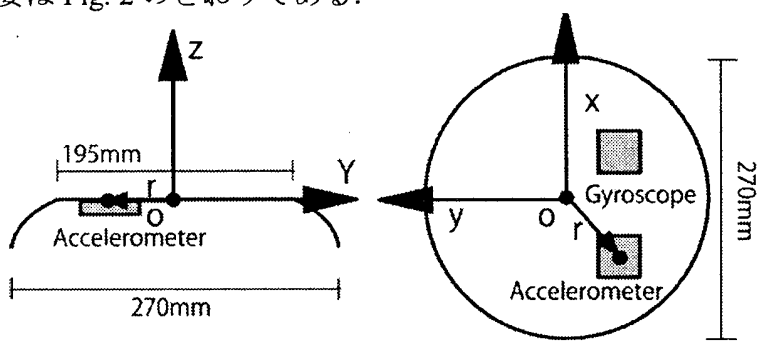

Fig. 1: Schematic illustration of the flying disc

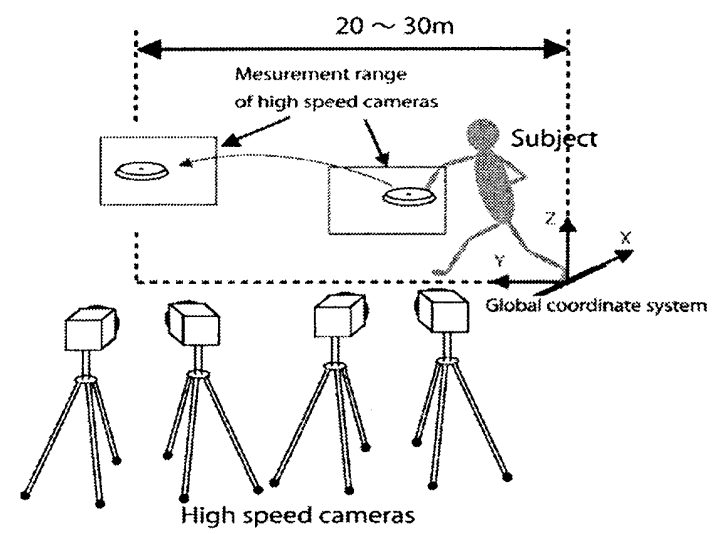

Fig. 2: Schematic illustration of the experiment

\section{3. 実験結果, 推定方法}

Figure 3 は実験により取得した飛翔期のフライングディス クの加速度データを示したものである. 飛翔中の加速度デー 夕は周期性を持ったデータとして示された．また，角速度の データも周期性を持ったデータとして示された(Fig. 4).

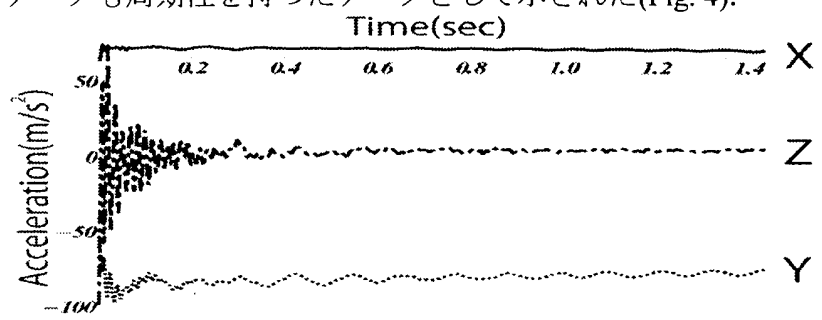

Fig. 3: Acceleration data during the flight 


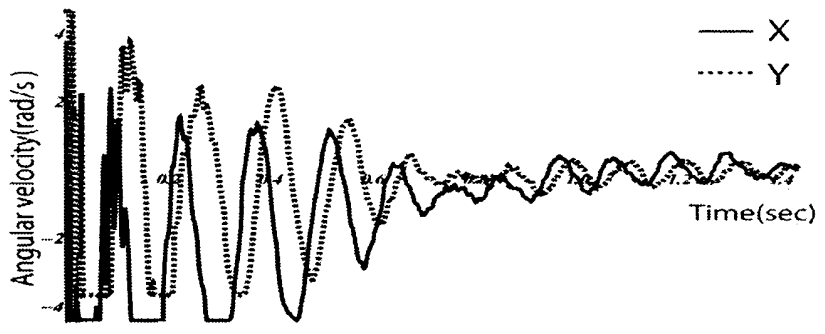

Fig. 3: Angular velocity data during the flight

運動する物体に固定された加速度計からは加速度は並進 加速度, 重力加速度, 遠心加速度, 接線加速度成分の 4 つの 成分が出力され，Fig. 3 の加速度データにもそれどれが何ら かの形で出力されている. 太田らは並進加速度計を使用して 運動体の角速度を推定する際以上のように加速度成分を区 分することで行った 3 ). 絶対座標系 $\Sigma X Y Z$ の原点を $\mathrm{O}$ とお き, 運動体に固定された運動座標系 $\Sigma x y z$ の原点を o とする. 物体が運動を行った際任意の点 $\mathrm{p}$ に生じる加速度 $\mathbf{A}$ は式(1) のように示すことが可能である.

$$
\mathbf{A}=\ddot{\mathbf{R}}+\boldsymbol{\omega} \times(\boldsymbol{\omega} \times \mathbf{r})+\dot{\boldsymbol{\omega}} \times \mathbf{r}-\mathbf{g}
$$

ここで $\mathbf{R}$ は絶詨座標系からみた 0 の位置ベクトル， $\mathbf{g}$ は重 力加速度, $\mathbf{r}$ は運動座標系からみた点 $\mathrm{p}$ の位置ベクトル, $\boldsymbol{\omega}$ は運動座標系からみた角速度ベクトルである.

Koyanagi et al. は検証実験によりセンサを内蔵させた球の 飛翔中のデータにそれぞれの成分がどのように出力されて いるかを示した 2).データ上に各加速度成分が表出する際に は遠心加速度が波形の DC 成分, 重力加速度及び並進加速度 については波形の振幅として出力されていることが明らか となった.この知見より, フライングディスクの運動学変量 を推定する際の波形の処理を行った。

\section{3-1. 角速度推定}

回転軸の方向を推定するため, $\mathrm{z}$ 軸の角速度を加速度計の 值を使用して推定した，推定には小柳らの知見を利用した 1)。デ。飛翔中のフライングディスクに固定した加速度計か ら推定した角速度 $\omega_{z}$ は以下の式(2)とおりである.

$$
\omega_{z}(t)=\sqrt{\frac{a_{x}^{\prime}(t)}{r_{x}}} \tanh \left(\sqrt{a_{x}^{\prime}(t) r_{x}} \omega_{z}(0)-\frac{\sqrt{a^{\prime}(t)_{x} r_{x}}}{r_{y}} t\right)
$$

ここで $r_{x}$ はセンサ座標系におけるディスクの中心とセンサ の中心との X 座標軸上の距離, $a_{x}^{\prime}$ は加速度データから重力 加速度及び並進加速度を除去したものである.

\section{3-2. 回転軸推定}

推定したセンサ座標系の $\mathrm{z}$ 軸方向の角速度及びジャイロ スコープにより計測した $\mathrm{x}, \mathrm{y}$ 軸の角速度より，回転軸を推 定した. 回転軸は角速度ベクトルの方向と一致しているため, それぞれの軸の角速度を単位ベクトル化し，ローカル座標系 での方向を推定した。

さらに絶対座標系からみた回転軸を求めるため, 飛翔期が 終了する直前の画像より, 高速度カメラから求めた絶対座標 系からみたセンサ座標系の方向を求めた. その座標から回転 行列を作り, センサ座標系での回転軸を絶対座標系へと座標 変換を行った。 さらに求めた角速度を数值積分することに よって角度を算出し， 0.001 秒間に各軸がどの程度動いてい るのかを求め回転行列に值を入力し, 絶対座標系をセンサ座 標系の関係を求め, その值を使用して飛翔期全体の絶対座標 系からみた回転軸の方向を求めた。推定の際, ジャイロス コープの出力値が振りきれている䇢所はベジェ曲線の手法 を使用して振りきれている籄所のデータを補間した。

\section{4. 結果}

\section{4-1. 角速度}

加速度計から推定した $\mathrm{z}$ 軸方向の角速度は以下のとおり
である(Fig. 4).

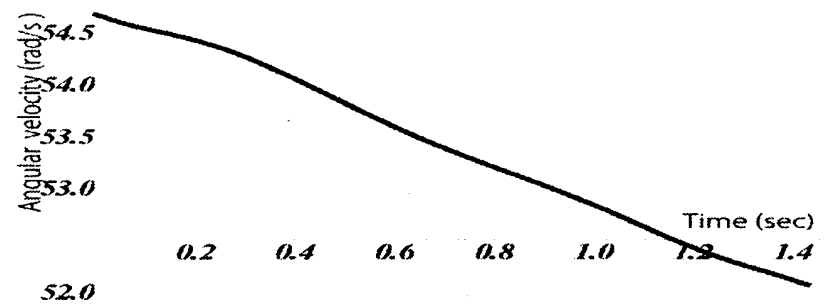

Fig. 4: Angular velocity of the $z$ axis

また, 高速度カメラで計測した值と加速度計を使用して推 定した值とを比較した. その際の高速度カメラの測定值とセ ンサの推定值ではその差異がリリース時で約 $0.13(\mathrm{rad} / \mathrm{s})$, 飛 翔期終了直前で約 $0.27(\mathrm{rad} / \mathrm{s})$ であった。

\section{4-2. 回転軸}

Figure 5 は高速度カメラで算出した回転軸の飛翔期終盤の值 と同時刻のセンサから推定した回転軸を比較したものであ る. 飛翔期終盤の高速度カメラの測定值とセンサの推定値と の差異は約 $4 \mathrm{deg}$ 程度であった. 図中の点線はカメラの計測 値, 実線がセンサの推定值となっている.



Fig. 5 : Comparison of the end phase rotational axis また Fig. 6 では, センサから推定した飛翔期全体の軸の方向 を示している．飛翔期の前半に行くほど誤差が大きくなり， 軸が大きく変化してしまっている.
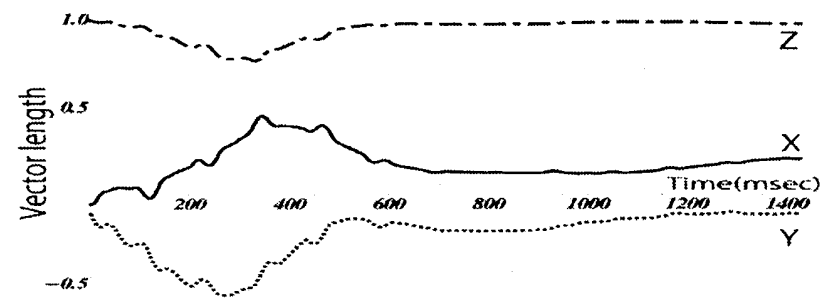

Fig. 6 : Whole phase rotational axis

5. おわりに

角速度の推定法については, ある程度の精度を持って推定 が可能であると考えられる.また回転軸の推定では特に飛翔 期前半の值が大きくずれてしまっていた.この誤差はジャイ ロスコープの值がリリース時に大きく増减している点や, 回 転行列に推定した角度を前の值加ら推定し入力するため, 誤 差が蓄積してしまっているものと考えられる. 今後この誤差 を修正するため, カルマンフィルタを使用した回転軸の推定 を考えている.さらにセンサ座標系と絶対座標系の関係が明 らかとなれば, 空気力の推定も容易に推定することが可能と なる.

\section{参考文献}

(1) 小柳玲乃, 仰木裕嗣, 加速度計を利用したフライング ディスクの運動学変量推定, ジョイント・シンポジゥム 2009 講演論文集, 09-45(2009), pp.401-404.

(2) Koyanagi, R., and Ohgi, Y., Measurement of the forces on ball in flight using built-in accelerometer. Proceedings of International Sports Engineering Association, 7-2(2008), pp. $1-8$.

（3）太田憲，小林一敏. 加速度計を用いたスポーツにおける 角速度 - 角加速度計測。計測自動制御, 30-12(1994), pp.1442-1448. 